\title{
Analyses of spatial variations of kenaf in experimental field
}

\author{
Dauda, T. O. ${ }^{1 \star}$, Asiribo, O. E. ${ }^{2}$, Adekeye, K. S. ${ }^{3}$ and Agbaje, G. A. ${ }^{1}$ \\ ${ }^{1}$ Institute of Agricultural Research and Training, Obafemi Awolowo University, PMB 5029, Moor Plantation, Ibadan, \\ Nigeria. \\ ${ }^{2}$ Statistics Department, University of Agriculture, PMB 2240, Abeokuta, Nigeria. \\ ${ }^{3}$ Statistics Department, Redeemers' University, Mowe, Ogun State, Nigeria.
}

Accepted 1 October, 2009

\begin{abstract}
Preliminary investigations of experimental field usually involve collection of soil samples at widely spaced locations which are patchily or globally at variant spatially. This study was carried out to evaluate spatial variations in experimental fields using a split plot experiment distributed in a completely randomized design at Ikenne and Ilora between June and September 2006 (test crop was kenaf). The preliminary descriptive statistics suggested the dependency of the stem girth and height on the spatial positions. The variance - covariance analyses matrices of the plots showed that stem girth and plant height were independently distributed and exhibited a non stationarity principle. The results also revealed that spatial autocorrelation exists in patches in the experimental fields while the entire plots showed random distributions because the autocorrelatons were neither dominated by negative nor positive correlation and more than $50 \%$ of these values falls within the range of $\pm 2 / \sqrt{ }$. From this study, a regionalized spatial variation is imminent in $625 \mathrm{~m}^{2}$ experimental plot despite the difference in the treatments. Spatial variations study was found necessary in any plot not more than an acre $\left(250 \mathrm{~m}^{2}\right)$ of land otherwise such variations should be treated as block or environmental effect(s).
\end{abstract}

Key words: Spatial variation, mean growth parameters, classical statistical analysis.

\section{INTRODUCTION}

Preliminary investigations of soils of experimental fields are usually carried out on soil samples collected at widely spaced locations which are patchily or globally different spatially. This is usually due to the fact that the spatial scales of variations in the variables being measured are not often known before sampling is done. Consequently, the outcome of such experiment is prone to error due to such spatial variation. Although one of the essence of randomization as well as replication is to eliminate errors due to variations but, spatial variation in the number of species in plots have been found to be caused by differrences with regards to the mean values in the blocks indicating differences in the site conditions (Presinger et al., 2000). It could also be due to differences in previous farming practices as well as land use, topography of the land and nutrient application inaccuracy, (Fulton et al.,

\footnotetext{
*Corresponding author. E-mail: taofikdaud@yahoo.com
}

1996; Vieira and Gonzalez, 2003). These may be quite beyond mere randomization or replication because the variations may be large enough to cause error.

Kenaf, Hibiscus cannabinus, is a short day annual herbaceous plant cultivated for the soft baste fiber in its stem and recently due to search for commercial fibre for the woody core fiber as well (Fike, 1990). Spatial statistic is concerned with the study of spatially referenced data and associated statistical models and processes (Song and Kulldorf, 2008). The need for the investigation of the validity of the assumptions of classical statistical analysis (CSA) cannot be over emphasized because it may results into inflation of the probability of a type I error in hypothesis test (Vieira and Gonzalez, 2003). One of the assumptions of CSA is that observations as well as error are assumed independent. However, agricultural experiments often contain spatial layout and or temporal correlation due to repeated sampling of measurements at the the same experimental unit. Indeed, lack of spatial independence in ecological data have been viewed as a 
problem that can obscure one's ability to understand the biology of the organism being studied, (Liebhold and Gurevitch, 2002). Also, spatial statistics analyses (SSA) have been described as inferential analysis which allows for more reliable inference to be made from data analysis results. Works on spatial statistics thus provide insight into field distribution of the data values to avoid unbridled generalization of the data behavious. Similarly, the nature of the spatial distribution of the data (whether random or otherwise) can be obtained through spatial statistic study (SSS). This study would thus boost the outcome of the results of any experimentation because of the incorporation spatial variability pattern (SVP) in the arrangement of experimental treatment and its consideration in the analysis of the data of the experiment. This work is therefore justified from the need to boost experimental design and analysis through provision of information about SVP in experimental plots. Therefore, there is need to boost experimental design through the provision of information about spatial variation in experimental plots which is the focus of this paper. The objective of this study is thus to evaluate spatial variation in experimental fields.

\section{MATERIALS AND METHODS}

\section{Experimental settings}

Data sets for this project were from two experiments set up at Ikenne and llora out stations of the Institute of Agricultural Research and Training, Ibadan between June and September 2006. The two (2) sample experiments were both on evaluation of the effect of fertilizer and insecticides on Kenaf. Ikenne falls within the forest zone $\left(27^{0} 48^{\prime} \mathrm{N}\right.$ and $\left.3^{0} 52^{\prime}\right)$ of the country while llora is located in the intermediate guinea savanna $\left(126^{\circ} 52^{\prime} \mathrm{N}\right.$ and $\left.3^{0} 41^{\prime}\right)$. Each of the experiment was carried out using split plot in a restricted completely randomized design. The main plot is the spraying regime $\left(\mathrm{S}_{1}=300 \mathrm{~kg} \mathrm{NPK}+100 \mathrm{~kg}\right.$ Furadan +2 pre flowering insecticide sprays and $S_{2}=600 \mathrm{~g} \mathrm{NPK}+200 \mathrm{~kg}$ Furadan +4 pre flowering insecticide sprays) while the sub plot was the varieties $\left(\mathrm{V}_{1}=\right.$ Cuba 108, $\mathrm{V}_{2}=$ Ifeken 400 and $\mathrm{V}_{3}=$ local cultivar). Data on stem girth and plant height were collected at interval of 2 weeks commencing at 4 weeks after planting and relative to their spatial positions. This was repeated five times (that is $4,6,8,10$ and 12 weeks after planting).

The data obtained from the experiment were evaluated for normal distribution using $\mathrm{D}^{2}$ plots, (Richard and Dean, 1998) and as well subjected to descriptive statistics including the mean and the variance (for each of the plots and for each of the experiments). Removal of treatment effects was done using:

$$
Z(x)=x_{i}-\left(\bar{x}-\bar{x}_{i}\right) . . \quad .
$$

where $\bar{x}$ is the mean of the original value regardless of the treatments and $x_{i}$ is growth values at plot i. $\bar{x}_{i}$ is the mean of the plots receiving the same treatment. Also, autocorrelations of the data from each plot over convenient time lag of 35 were computed. Autocorrelation on the other hand is defined as the correlation of a variable in time and space with itself, (Schanbenberger and Pierce, 2002). The autocorrelation between observation at plot $x_{i}$ and $x_{j}$ is measured by the correlation.

$$
\operatorname{Corr}\left[Y\left(x_{i}\right), Y\left(x_{j}\right)\right]=\frac{\operatorname{Cov}\left[Y\left(x_{i}\right), Y\left(x_{j}\right)\right]}{\sqrt{\operatorname{Var}\left[Y\left(x_{i}\right)\right] \operatorname{Var}\left[Y\left(x_{j}\right)\right]}}
$$

The estimation of spatial variability effects were based on the spatial distances of the neighbouring plots to the referenced plots. Six different spatial distance groups were obtained and the distances are; $4.243,3.606,3.163,2.828,2.236$ and $1.414 \mathrm{~m}$. Members of the distance group range between 4 and 8 because some of the distances are unique (by repeating themselves in each of the quadrant) while, some are not.

\section{RESULTS}

\section{Descriptive statistics and test for normality}

Assuming the set of all points on an experimental plot is denoted by $\{Z(s): s \in D\}$ where $s$ represents a spatial location vector in $R$ and $D$ defines a finite region of the plot. A set of measurements $\left\{Z\left(s_{1}\right), \ldots, Z\left(s_{n}\right)\right\}$ adjusted for treatment means at known location $s_{1}, \ldots, s_{n}$ are as contained in Table 1. It was noted that plots at different location returned different mean plant heights and no regular pattern was suspected across the different plots. It was also observed that the same plots that returned the highest plant height returned the highest stem girth, (Table 1). Similarly, the same plot that returned the least plant height had the least stem girth. This suggests similarity in the trend of variability of the 2 different growth indices (height and stem girth). However, the trends of variance obtained for the different growth indices were not similar with the means because the plots that returned the highest means for the various indices were not the one that returned same for the variance, (Table 1). At llora, the plot variability cannot be associated with the effects of the treatment on the plant because the same treatment that returned the highest mean value returned the lowest mean value at different plots location. The highest and least variances were equally not treatment dependent. For the plot variability at Ikenne however, the possible effects of the treatments could be suspected because the different treatments had both the highest and least mean height and stem girth. This was however contradicted by the fact that the trend was not maintained for both indices (height and stem girth). It could be obtained from these results that for stem girth at both sites no 2 plots of the same or different treatment had the same means. This is however different from the variances at the 2 sites (Ilora and Ikenne). For the stem girth at llora, some plots $(17 \%)$ of the same treatments $\left(\mathrm{V}_{1} \mathrm{~S}_{1}\right)$ as well as others of different treatments but neighbours returned similar/the same variance. However, for stem girth at Ikenne, all plots having the same/similar variance are of different treatment but neighbours (Table 1). Two plots $\left(x_{3,5}\right.$ and $\left.x_{4,5}\right)$ at llora returning the same 
Table 1. Means and variances of different variables at different plots irrespective of the weeks.

\begin{tabular}{|c|c|c|c|c|c|c|c|c|c|}
\hline Treatment & $\begin{array}{c}\text { Plot } \\
\text { Address }\end{array}$ & $\begin{array}{l}\text { Stem girth - } \\
\text { (cm) (Ilora) }\end{array}$ & Variance & $\begin{array}{l}\text { Stem girth- } \\
\text { (cm) } \\
\text { (Ikenne) }\end{array}$ & Variance & $\begin{array}{l}\text { Height } \\
\text { (cm ) } \\
\text { (Ilora) }\end{array}$ & Variance & $\begin{array}{l}\text { Height } \\
\text { (cm) } \\
\text { (Ikenne) }\end{array}$ & Variance \\
\hline V1S1 & 1,1 & 0.582 & 0.039 & 0.825 & 0.023 & 78.604 & 727.327 & 100.968 & 852.406 \\
\hline V1S1 & 1,2 & 0.660 & 0.063 & 0.824 & 0.042 & 92.388 & 928.969 & 73.893 & 797.328 \\
\hline V1S1 & 1,3 & 0.642 & 0.043 & 0.998 & 0.079 & 67.452 & 672.832 & 83.448 & 1448.335 \\
\hline V1S1 & 1,4 & 0.737 & 0.043 & 1.178 & 0.192 & 108.376 & 761.429 & 131.812 & 2236.439 \\
\hline V1S1 & 1,5 & 0.816 & 0.043 & 1.166 & 0.132 & 116.092 & 791.860 & 141.060 & 3577.834 \\
\hline V1S1 & 1,6 & 0.641 & 0.033 & 0.941 & 0.033 & 59.192 & 454.969 & 75.736 & 558.897 \\
\hline V2S1 & 2,1 & 0.518 & 0.043 & 0.758 & 0.041 & 43.640 & 177.289 & 64.028 & 851.239 \\
\hline V2S1 & 2,2 & 0.627 & 0.034 & 0.754 & 0.062 & 54.184 & 301.752 & 46.984 & 672.676 \\
\hline V2S1 & 2,3 & 0.708 & 0.031 & 1.256 & 0.162 & 96.872 & 911.496 & 126.168 & 2917.620 \\
\hline V2S1 & 2,4 & 0.744 & 0.032 & 1.232 & 0.176 & 99.304 & 545.690 & 136.256 & 2121.984 \\
\hline V2S1 & 2,5 & 0.987 & 0.057 & 1.118 & 0.125 & 133.704 & 770.340 & 139.672 & 2504.302 \\
\hline V2S1 & 2,6 & 0.762 & 0.025 & 1.026 & 0.054 & 98.316 & 535.321 & 118.052 & 2577.796 \\
\hline V3S1 & 3,1 & 0.534 & 0.031 & 0.844 & 0.034 & 74.060 & 549.246 & 89.316 & 723.825 \\
\hline V3S1 & 3,2 & 0.611 & 0.023 & 0.829 & 0.064 & 82.460 & 370.370 & 71.108 & 744.144 \\
\hline V3S1 & 3,3 & 0.791 & 0.057 & 1.225 & 0.292 & 113.108 & 656.282 & 122.820 & 2174.450 \\
\hline V3S1 & 3,4 & 0.809 & 0.103 & 1.033 & 0.117 & 72.168 & 880.843 & 99.068 & 2256.535 \\
\hline V3S1 & 3,5 & 0.627 & 0.019 & 0.965 & 0.097 & 44.920 & 302.203 & 97.464 & 1991.748 \\
\hline V3S1 & 3,6 & 0.638 & 0.017 & 0.963 & 0.047 & 54.336 & 454.670 & 125.520 & 2932.981 \\
\hline V2S2 & 4,1 & 0.695 & 0.036 & 0.856 & 0.047 & 95.556 & 437.521 & 84.032 & 556.016 \\
\hline V2S2 & 4,2 & 0.639 & 0.044 & 0.860 & 0.067 & 58.044 & 294.328 & 86.812 & 1380.568 \\
\hline V2S2 & 4,3 & 0.665 & 0.038 & 0.986 & 0.101 & 64.672 & 488.808 & 98.992 & 2479.741 \\
\hline V2S2 & 4,4 & 0.851 & 0.044 & 1.266 & 0.135 & 123.160 & 1510.566 & 155.940 & 3644.054 \\
\hline V2S2 & 4,5 & 0.581 & 0.056 & 0.896 & 0.023 & 44.920 & 302.203 & 74.508 & 642.724 \\
\hline V2S2 & 4,6 & 0.623 & 0.035 & 0.958 & 0.049 & 54.300 & 456.036 & 68.760 & 568.775 \\
\hline V3S2 & 5,1 & 0.676 & 0.035 & 0.766 & 0.046 & 52.260 & 302.273 & 66.172 & 854.861 \\
\hline V3S2 & 5,2 & 0.725 & 0.034 & 1.096 & 0.105 & 109.504 & 1138.860 & 139.328 & 3084.581 \\
\hline V3S2 & 5,3 & 0.777 & 0.030 & 1.256 & 0.170 & 118.012 & 435.807 & 134.156 & 2563.701 \\
\hline V3S2 & 5,4 & 0.797 & 0.060 & 1.194 & 0.109 & 108.952 & 702.939 & 148.384 & 2746.284 \\
\hline V3S2 & 5,5 & 0.688 & 0.042 & 1.032 & 0.062 & 102.164 & 1021.825 & 128.220 & 2735.813 \\
\hline V3S2 & 5,6 & 0.784 & 0.029 & 0.988 & 0.166 & 108.184 & 510.308 & 112.768 & 3516.609 \\
\hline V1S2 & 6,1 & 0.690 & 0.028 & 0.776 & 0.062 & 94.804 & 477.117 & 75.252 & 734.898 \\
\hline V1S2 & 6,2 & 0.798 & 0.031 & 1.187 & 0.134 & 117.920 & 1089.066 & 130.636 & 2046.241 \\
\hline V1S2 & 6,3 & 0.844 & 0.052 & 1.206 & 0.177 & 120.408 & 953.019 & 125.096 & 2373.249 \\
\hline V1S2 & 6,4 & 0.774 & 0.099 & 1.058 & 0.075 & 79.740 & 414.530 & 106.732 & 2325.458 \\
\hline V1S2 & 6,5 & 0.762 & 0.028 & 0.912 & 0.023 & 105.672 & 890.485 & 124.648 & 3102.044 \\
\hline V1S2 & 6,6 & 0.753 & 0.015 & 0.975 & 0.064 & 103.504 & 290.515 & 124.908 & 4438.358 \\
\hline
\end{tabular}

mean plant height and variance were of different treatment $\left(\mathrm{V}_{3} \mathrm{~S}_{1}\right.$ and $\left.\mathrm{V}_{2} \mathrm{~S}_{2}\right)$. For the plant height at Ikenne on the other hand, no 2 plots returned the same mean or the same variance (Table 1). The implication of this is the stability of the variance for some plots (usually neighbouring plots) and in patches. For the spatial variability effects of the stem girth at both sites, no 2 plots returned the same mean or variance. This is equally true of the plant height at both sites (Table 2). The implication of this is that spatial variation in experimental plots could be associated with spatial address and distribution of the various plots. The spatial variability effect is found to be additive because the difference between the values with and without the treatment effects obtained for all plots is unity (Table 2).

The bivariate normality plots of the two indices (stem girth and plant height) at both stations followed a near linear and increasing trend, (Figure 1). This implied that plot variability notwithstanding the data from the experiment is still normally distributed. Also, worthy of note is that the trend is lower at the llora station for both girth and plant height than Ikenne. This was because the $D^{2}$ 
Table 2. Means of different variables (with and without treatment) at different plots irrespective of the weeks.

\begin{tabular}{|c|c|c|c|c|c|c|c|c|c|c|c|c|}
\hline \multirow[t]{2}{*}{ plot } & \multicolumn{4}{|c|}{ Plots with treatment effects } & \multicolumn{4}{|c|}{ Plots without treatment effects } & \multicolumn{4}{|c|}{ Differences } \\
\hline & $V_{1}$ & $V_{2}$ & $V_{3}$ & $V_{4}$ & $V_{1}$ & $V_{2}$ & $V_{3}$ & $V_{4}$ & $V_{1}$ & $V_{2}$ & $V_{3}$ & $V_{4}$ \\
\hline 1 & 0.582 & 0.825 & 78.604 & 100.968 & -0.418 & -0.175 & 77.604 & 99.968 & 1 & 1 & 1 & 1 \\
\hline 2 & 0.660 & 0.824 & 92.388 & 73.893 & -0.340 & -0.176 & 91.388 & 72.893 & 1 & 1 & 1 & 1 \\
\hline 3 & 0.642 & 0.998 & 67.452 & 83.448 & -0.358 & -0.002 & 66.452 & 82.448 & 1 & 1 & 1 & 1 \\
\hline 4 & 0.737 & 1.178 & 108.376 & 131.812 & -0.263 & 0.178 & 107.376 & 130.812 & 1 & 1 & 1 & 1 \\
\hline 5 & 0.816 & 1.166 & 116.092 & 141.060 & -0.184 & 0.166 & 115.092 & 140.060 & 1 & 1 & 1 & 1 \\
\hline 6 & 0.641 & 0.941 & 59.192 & 75.736 & -0.359 & -0.059 & 58.192 & 74.736 & 1 & 1 & 1 & 1 \\
\hline 7 & 0.519 & 0.758 & 43.640 & 64.028 & -0.481 & -0.242 & 42.640 & 63.028 & 1 & 1 & 1 & 1 \\
\hline 8 & 0.628 & 0.754 & 54.184 & 46.984 & -0.372 & -0.246 & 53.184 & 45.984 & 1 & 1 & 1 & 1 \\
\hline 9 & 0.708 & 1.256 & 96.872 & 126.168 & -0.292 & 0.256 & 95.872 & 125.168 & 1 & 1 & 1 & 1 \\
\hline 10 & 0.744 & 1.232 & 99.304 & 136.256 & -0.256 & 0.232 & 98.304 & 135.256 & 1 & 1 & 1 & 1 \\
\hline 11 & 0.987 & 1.118 & 133.704 & 139.672 & -0.013 & 0.118 & 132.704 & 138.672 & 1 & 1 & 1 & 1 \\
\hline 12 & 0.762 & 1.026 & 98.316 & 118.052 & -0.238 & 0.026 & 97.316 & 117.052 & 1 & 1 & 1 & 1 \\
\hline 13 & 0.534 & 0.844 & 74.060 & 89.316 & -0.466 & -0.156 & 73.060 & 88.316 & 1 & 1 & 1 & 1 \\
\hline 14 & 0.611 & 0.829 & 82.460 & 71.108 & -0.389 & -0.171 & 81.460 & 70.108 & 1 & 1 & 1 & 1 \\
\hline 15 & 0.791 & 1.225 & 113.108 & 122.820 & -0.209 & 0.225 & 112.108 & 121.820 & 1 & 1 & 1 & 1 \\
\hline 16 & 0.809 & 1.033 & 72.168 & 99.068 & -0.191 & 0.033 & 71.168 & 98.068 & 1 & 1 & 1 & 1 \\
\hline 17 & 0.627 & 0.965 & 44.920 & 97.464 & -0.373 & -0.035 & 43.920 & 96.464 & 1 & 1 & 1 & 1 \\
\hline 18 & 0.638 & 0.963 & 54.336 & 125.520 & -0.362 & -0.037 & 53.336 & 124.520 & 1 & 1 & 1 & 1 \\
\hline 19 & 0.696 & 0.856 & 95.556 & 84.032 & -0.304 & -0.144 & 94.556 & 83.032 & 1 & 1 & 1 & 1 \\
\hline 20 & 0.639 & 0.860 & 58.044 & 86.812 & -0.361 & -0.140 & 57.044 & 85.812 & 1 & 1 & 1 & 1 \\
\hline 21 & 0.665 & 0.986 & 64.672 & 98.992 & -0.335 & -0.014 & 63.672 & 97.992 & 1 & 1 & 1 & 1 \\
\hline 22 & 0.851 & 1.266 & 123.160 & 155.940 & -0.149 & 0.266 & 122.160 & 154.940 & 1 & 1 & 1 & 1 \\
\hline 23 & 0.581 & 0.896 & 44.920 & 74.508 & -0.419 & -0.104 & 43.920 & 73.508 & 1 & 1 & 1 & 1 \\
\hline 24 & 0.623 & 0.958 & 54.300 & 68.760 & -0.377 & -0.042 & 53.300 & 67.760 & 1 & 1 & 1 & 1 \\
\hline 25 & 0.676 & 0.766 & 52.260 & 66.172 & -0.324 & -0.234 & 51.260 & 65.172 & 1 & 1 & 1 & 1 \\
\hline 26 & 0.725 & 1.096 & 109.504 & 139.328 & -0.275 & 0.096 & 108.504 & 138.328 & 1 & 1 & 1 & 1 \\
\hline 27 & 0.777 & 1.256 & 118.012 & 134.156 & -0.223 & 0.256 & 117.012 & 133.156 & 1 & 1 & 1 & 1 \\
\hline 28 & 0.797 & 1.194 & 108.952 & 148.384 & -0.203 & 0.194 & 107.952 & 147.384 & 1 & 1 & 1 & 1 \\
\hline 29 & 0.688 & 1.032 & 102.164 & 128.220 & -0.312 & 0.032 & 101.164 & 127.220 & 1 & 1 & 1 & 1 \\
\hline 30 & 0.784 & 0.988 & 108.184 & 112.768 & -0.216 & -0.012 & 107.184 & 111.768 & 1 & 1 & 1 & 1 \\
\hline 31 & 0.690 & 0.776 & 94.804 & 75.252 & -0.310 & -0.224 & 93.804 & 74.252 & 1 & 1 & 1 & 1 \\
\hline 32 & 0.798 & 1.188 & 117.920 & 130.636 & -0.202 & 0.188 & 116.920 & 129.636 & 1 & 1 & 1 & 1 \\
\hline 33 & 0.844 & 1.206 & 120.408 & 125.096 & -0.156 & 0.206 & 119.408 & 124.096 & 1 & 1 & 1 & 1 \\
\hline 34 & 0.774 & 1.058 & 79.740 & 106.732 & -0.226 & 0.058 & 78.740 & 105.732 & 1 & 1 & 1 & 1 \\
\hline 35 & 0.762 & 0.912 & 105.672 & 124.648 & -0.238 & -0.088 & 104.672 & 123.648 & 1 & 1 & 1 & 1 \\
\hline 36 & 0.753 & 0.975 & 103.504 & 124.908 & -0.247 & -0.025 & 102.504 & 123.908 & 1 & 1 & 1 & 1 \\
\hline
\end{tabular}

$\mathrm{V}_{1}=$ Stem girth, Ilora, $\mathrm{V}_{2}=$ Stem girth, Ikenne, $\mathrm{V}_{3}=$ Plant height, Ilora, and $\mathrm{V}_{4}=$ Plant height, Ikenne.

plot of the llora station crosses the $y$-axis at 0.7 while that of the lkenne crosses the $y$-axis at 0.98 . For plant height also, the llora $D^{2}$ crosses the $y$-axis at 98 while that of Ikenne crosses at 110 . These implied that the data sets obtained for both indices at lkenne were higher than those obtained from llora and that they do not satisfied the assumption of normality. The results of run test for the different variables (stem girth and plant height) at both station (Ilora and Ikenne) using matrix $A=a_{i j}, i=$ llora and lkenne, $j=$ stem girth and plant height.

$$
A=\left(\begin{array}{ll}
17.0 & 3.50 \\
3.50 & 2.50
\end{array}\right)
$$

This showed that similar data are followed by dissimilar ones indicating randomness of the data.

The autocorrelation values of the stem girth at Ilora ranged from -0.282 to 0.660 while those of Ikenne ranged between -0.465 to 0.718 . Similarly, the autocor- 

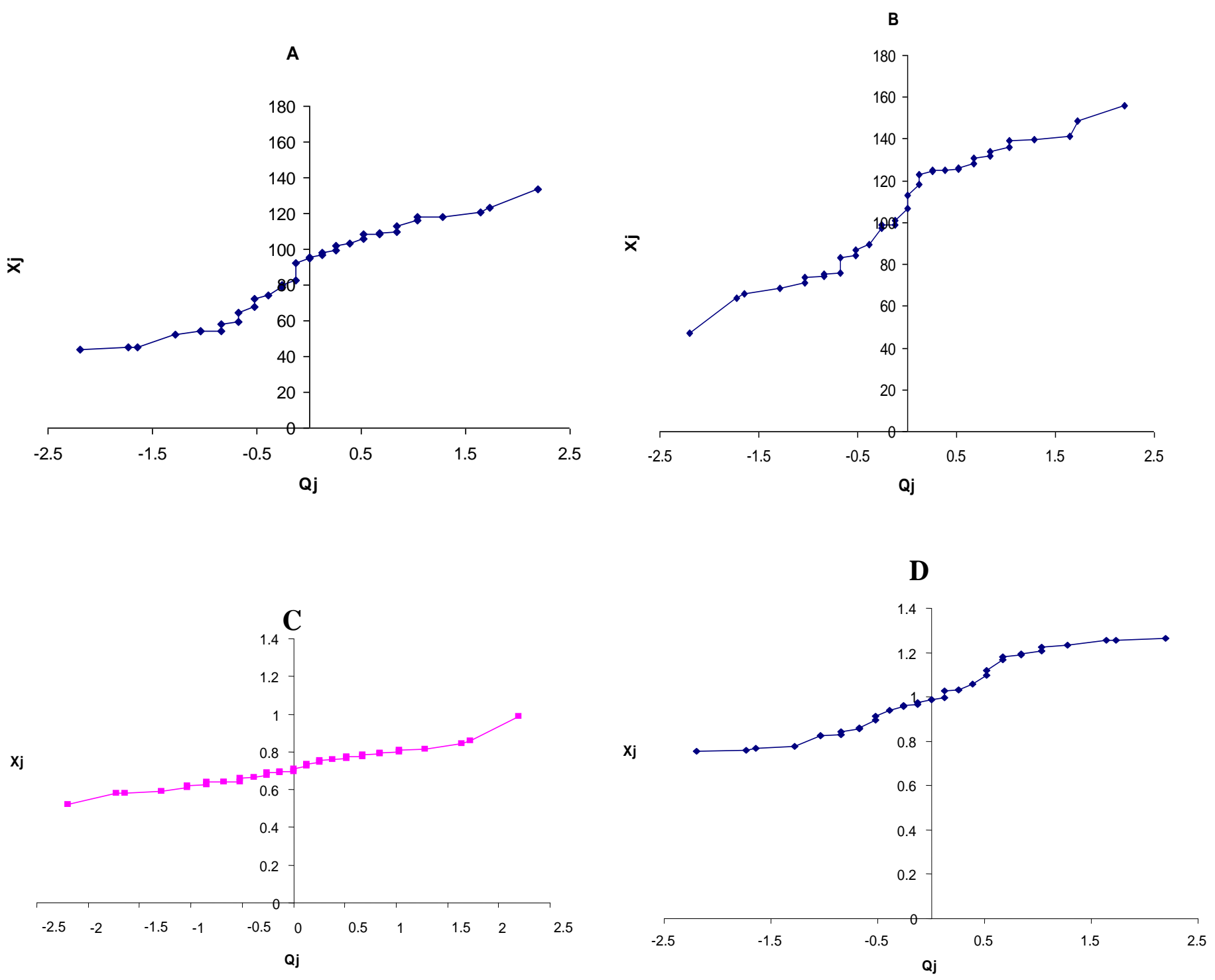

Figure 1. Multivariate analysis of kenaf plant height at Ilora (A) and lkenne (B) and stem girth at llora (C) and Ikenne (D).

relation values of the plant height at both stations showed that those of plant height at llora ranged between -0.715 and 0.563 while those of Ikenne ranged from -0.396 to 0.711 (Table 3). The autocorrelation of both variables at both sites were random. That is, the autocorrelation values were neither dominated by negative nor positive autocorrelation. Also, the autocorrelation values for the different variables at both sites returned the same trends (positive and negative) at the same lag and for the same number of lag (Table 3). The only exception to the number of negative autocorrelation values was the stem girth at llora where only $45 \%$ of the autocorrelation values were negative unlike others where $65 \%$ of the autocorrelation values were negative. The correlelogram for both stem girth and plant height at both sides followed an alternating series with successive observations on different sides of the overall means, (Figures $1 \mathrm{~A}$ and $\mathrm{B}$ ). Also, more than $50 \%$ of the autocorrelation values falls within the range of $\pm 2 / \sqrt{n}$ which equals to \pm 0.333 thus the residual is random and for large $n, r_{k}-N(0,1 / n)$ approximately. The autocorrelation values for the Ikenne stem girth however need some forms of appropriation, because less than $50 \%$ of the value falls within the range of $\pm 2 / \sqrt{n}$ (Table $3)$. It therefore indicated that this data differs from white noise and would need some forms of appropriation. The correlelogram of the spatial variability effects (SVE) for both stem girth and plant height showed a more alternating and reducing series as the lag increases (Figures 2A, B, C and D). The implication of this is that the correlelogram of the SVE followed the same pattern as with the treatment and that the SVE is an additive implication of lack of autocorrelation in the entire plot. 
Table 3. Autocorrelation table at Lag K = 35.

\begin{tabular}{|c|c|c|c|c|c|c|c|c|}
\hline \multirow{3}{*}{ Lag distance } & \multicolumn{4}{|c|}{ With treatment effects } & \multicolumn{4}{|c|}{ Without treatment effects } \\
\hline & \multicolumn{2}{|c|}{ Stem girth } & \multicolumn{2}{|c|}{ Plant height } & \multicolumn{2}{|c|}{ Stem girth } & \multicolumn{2}{|c|}{ Plant height } \\
\hline & Ilora & Ikenne & Ilora & Ikenne & Ilora & Ikenne & Ilora & Ikenne \\
\hline 1 & 0.244 & 0.237 & 0.293 & 0.242 & 0.244 & 0.237 & 0.228 & 0.242 \\
\hline 2 & -0.272 & -0.372 & -0.062 & -0.244 & -0.272 & -0.372 & -0.146 & -0.244 \\
\hline 3 & -0.202 & -0.573 & -0.026 & -0.446 & -0.202 & -0.573 & -0.055 & -0.447 \\
\hline 4 & -0.056 & -0.164 & 0.055 & -0.071 & -0.056 & -0.164 & 0.129 & -0.071 \\
\hline 5 & 0.177 & 0.36 & 0.012 & 0.099 & 0.177 & 0.360 & 0.014 & 0.099 \\
\hline 6 & 0.396 & 0.587 & 0.053 & 0.368 & 0.396 & 0.588 & 0.042 & 0.368 \\
\hline 7 & 0.102 & 0.042 & 0.08 & 0.13 & 0.102 & 0.042 & 0.012 & 0.130 \\
\hline 8 & -0.25 & -0.423 & -0.154 & -0.12 & -0.250 & -0.423 & -0.146 & -0.120 \\
\hline 9 & -0.393 & -0.43 & -0.215 & -0.244 & -0.393 & -0.430 & -0.197 & -0.244 \\
\hline 10 & -0.029 & -0.069 & -0.021 & -0.004 & -0.029 & -0.069 & 0.076 & -0.004 \\
\hline 11 & 0.281 & 0.289 & 0.082 & 0.179 & 0.281 & 0.289 & 0.170 & 0.179 \\
\hline 12 & -0.013 & 0.314 & -0.255 & 0.005 & -0.013 & 0.314 & -0.218 & 0.005 \\
\hline 13 & -0.122 & -0.029 & -0.142 & -0.061 & -0.122 & -0.029 & -0.124 & -0.061 \\
\hline 14 & -0.132 & -0.329 & -0.106 & -0.182 & -0.132 & -0.329 & -0.046 & -0.182 \\
\hline 15 & -0.15 & -0.205 & -0.093 & -0.118 & -0.150 & -0.205 & -0.099 & -0.118 \\
\hline 16 & 0.112 & -0.039 & 0.011 & 0.022 & 0.112 & -0.039 & -0.064 & 0.022 \\
\hline 17 & 0.241 & 0.382 & 0.283 & 0.414 & 0.241 & 0.382 & 0.193 & 0.414 \\
\hline 18 & 0.045 & 0.31 & 0.098 & 0.166 & 0.045 & 0.310 & 0.093 & 0.166 \\
\hline 19 & -0.06 & -0.083 & -0.153 & -0.165 & -0.060 & -0.083 & -0.234 & -0.166 \\
\hline 20 & -0.116 & -0.314 & -0.094 & -0.284 & -0.116 & -0.314 & -0.206 & -0.284 \\
\hline 21 & -0.021 & -0.167 & 0.008 & -0.08 & -0.021 & -0.167 & 0.096 & -0.080 \\
\hline 22 & 0.155 & 0.109 & 0.077 & 0.045 & 0.155 & 0.109 & 0.022 & 0.045 \\
\hline 23 & 0.086 & 0.311 & -0.014 & 0.166 & 0.086 & 0.311 & -0.059 & 0.166 \\
\hline 24 & 0.027 & 0.136 & -0.001 & 0.043 & 0.027 & 0.136 & -0.102 & 0.043 \\
\hline 25 & -0.049 & -0.167 & -0.055 & -0.045 & -0.050 & -0.168 & -0.036 & -0.045 \\
\hline 26 & -0.139 & -0.245 & -0.062 & -0.124 & -0.139 & -0.245 & -0.017 & -0.124 \\
\hline 27 & -0.095 & -0.064 & -0.023 & -0.081 & -0.095 & -0.065 & 0.023 & -0.082 \\
\hline 28 & -0.003 & 0.099 & 0.012 & -0.008 & -0.003 & 0.099 & 0.054 & -0.008 \\
\hline 29 & -0.047 & 0.109 & -0.062 & -0.015 & -0.047 & 0.109 & -0.013 & -0.015 \\
\hline 30 & -0.019 & 0.003 & -0.028 & -0.034 & -0.019 & 0.003 & -0.048 & -0.034 \\
\hline 31 & -0.048 & -0.099 & 0.036 & 0.013 & -0.048 & -0.099 & 0.080 & 0.013 \\
\hline 32 & -0.067 & -0.055 & -0.015 & -0.002 & -0.067 & -0.055 & 0.067 & -0.002 \\
\hline 33 & -0.04 & 0.009 & -0.007 & -0.036 & -0.040 & 0.009 & -0.033 & -0.036 \\
\hline 34 & -0.026 & 0.025 & -0.003 & -0.024 & -0.026 & 0.025 & 0.022 & -0.024 \\
\hline
\end{tabular}

This does not however indicate total non autocorrelation because spatial autocorrelation have been suspected in effect (Table 2). In addition, the autocorrelation length of the stem girth with treatment inclusive were $x_{28}$ for stem girth, llora and $x_{33}$ for stem girth at Ikenne. For plant height at llora, the autocorrelation length was $x_{34}$ while that of Ikenne was $x_{31}$. The autocorrelation length of the spatial variability effects for the stem girth at llora was found to be $x_{27}$ while that of stem girth at Ikenne was $x_{32}$ (Figure 2C and D). For the plant height at llora, autocorrelation length of the spatial variability effects was $x_{26}$ while that of plant height at Ikenne was $x_{30}$. Thus, it could be observed that the autocorrelation length of the spatial variability effects were shorter than those incurporating the treatment effects.

\section{DISCUSSION}

From the descriptive statistics, the spatial variability pattern (SVP) was observed to differ for different environment while it is similar for related growth indices. The similarity of the SVP for related growth variable could be hinged on the relationships existing between such related variables. Dauda et al. (2003) for instance have used a linear regression models to explain the relationships 
A

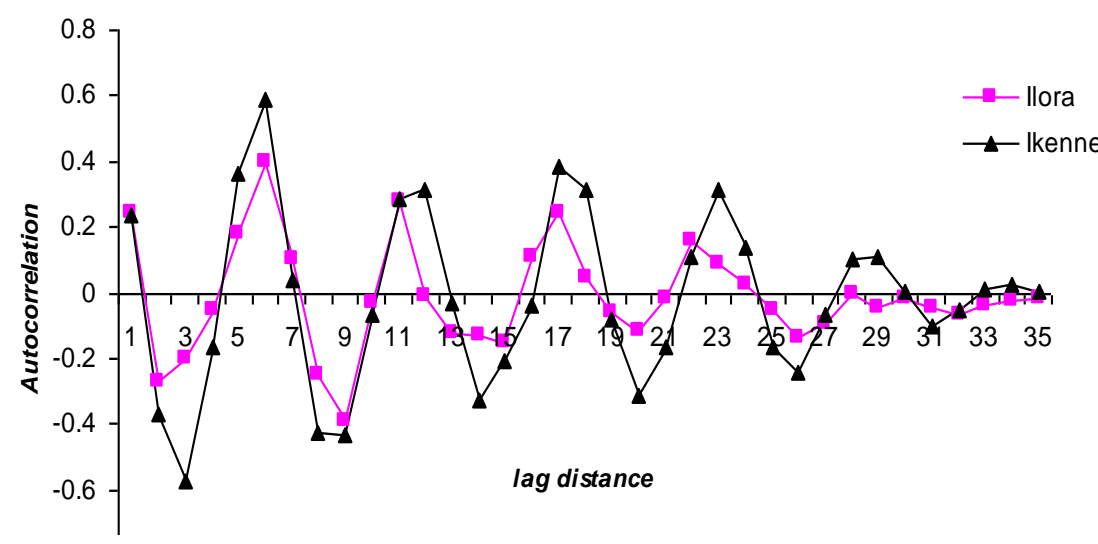

C

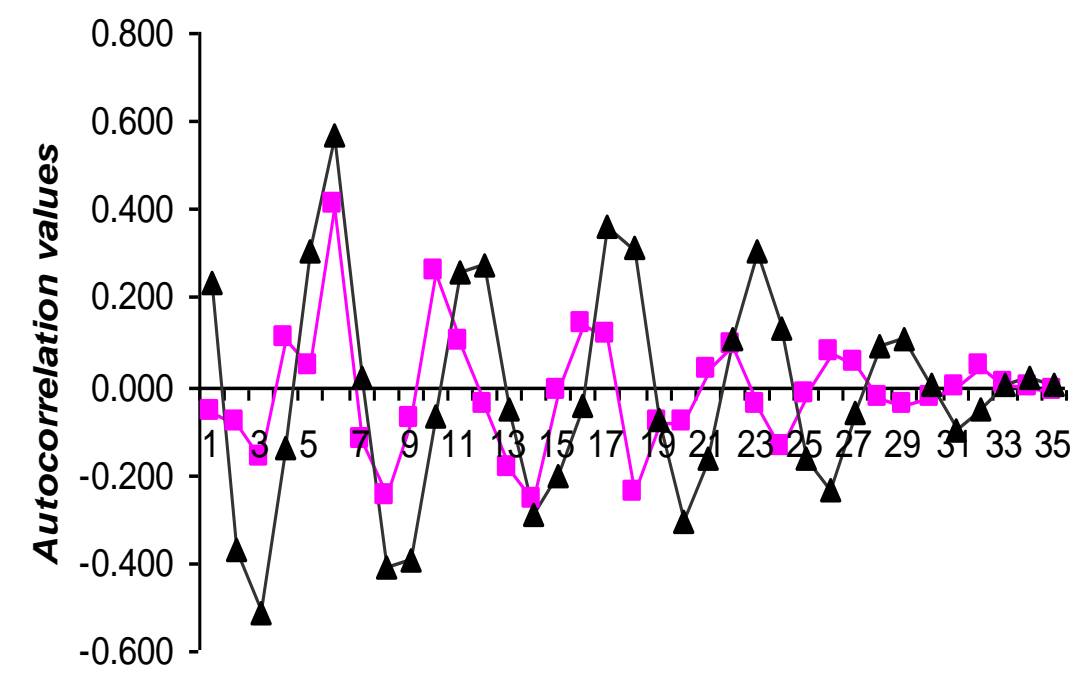

lag distances
B

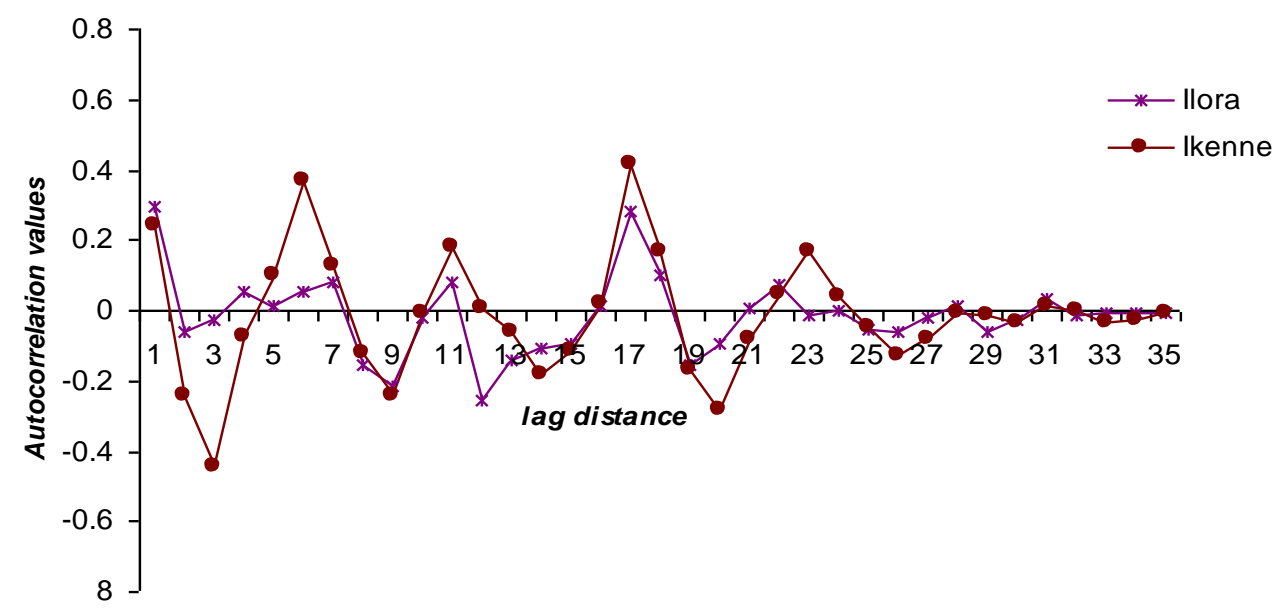

D

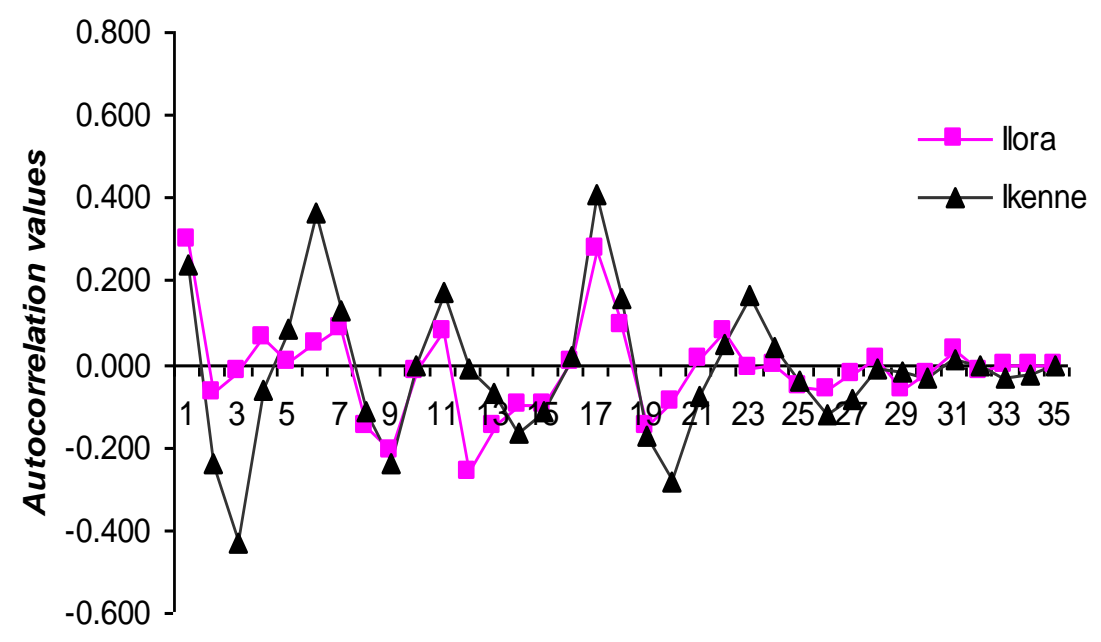

lag distances

Figure 2. Correlelograms of the stem girth (A) and Kenaf plant height (B) as well as spatial variability effect of stem girth (C) and Kenaf plant height (D) at both Ilora and Ikenne. 
between height and diameter at breast height of selected tree species. The SVP which include spatial variability and spatial similarities were suspected in patches. This is in contrast with Pfoser et al. (2000)'s approach of recording positional information for mobile objects. The suggested approach reduces objects to point data while ignoring their spatial extent. This disparity can however be hinged on the difference in the objects and change nature of such objects used by Pfoser et al. (2000) and this study. Two possible causes have so far been linked with spatial heterogeneity in any environment and are either naturally induced causes or artificially induced. It is also interesting to note that while spatial heterogeneity have been found to be caused by variety of disturbances and other biotic and abiotic factors in natural environment (Benwell et al., 2002) spatial heterogeneity in experimental field on the other hand could probably be traced to the naturally occurring situation to which treatment effects are cumulative.

The persistence of the highest plant height at the same plots could be hinged on the fact that the growth of plant is usually cumulative. The autocorrelation pattern as obtained form the result of this study is a function of the parameter because, while the stem girth of both sites produced similar autocorrelation on one hand, the plant height of the two sites produced different autocorrelation on the other hand. This similarity exhibited by these parameters implied proximity of observation. Exhibition of spatial autocorrelation is said to be a function of the proximity of observation (Schabenberger and Pierce, 2000). The irregular pattern of autocorrelation is an patches in the entire plots. The size of the range of autocorrelation values can be traced to the size of the data $\mathrm{Z}\left(\mathrm{s}_{\mathrm{i}}\right)$ obtained at each plots. That is $\gamma(\tau)=f\left\{Z\left(x_{i}\right)\right.$ and this autocorrelation of the datasets was shown in patches pattern. This was noticeable in the negative ridge displayed in 4 patches and across growth variables and sites. Lastly, the autocorrelation patterns were similar for both variables and sites but the size of the values of the parameters differs. In addition, randomness of the datasets was though obtained but autocorrelation of the datasets which were suspected in patches must be taken into consideration for proper model estimation. By this confirmation of randomness therefore, the univariate process can be modeled thus;

$Y_{i}=A_{0}+\varepsilon$

Where $\varepsilon_{i}$ is an error term, the $Y_{i}$ is the autocorrelation and $A_{0}$ is the lag period. Randomness as obtained from the autocorrelation and the correlelogram however has been said to be one of the three forms of spatial arrangements, (Benwell et al., 2002; Fagroud and Meirvenne, 2002). Others are clustered (where points are concentrated in one or more areas forming groups) and scattered uniform (when the points are distributed evenly).
These three forms can be found in any experimental field. The issue of spatial variability and uncertainty to conclude are often and widely discussed in geography and ecology due to dynamics of natural process. It had been less explored in agricultural field because activities on the agricultural field are artificially influenced.

However, based on this study spatial variability study is inevitable for any experimental field because;

i). The artificial influence on agricultural field notwithstanding, the baseline of these activities is still natural. For instance, the fertilization in this study would be influenced by the initial nutrients variability existing within the experimental plots. The artificial activities would thus be cumulative to the natural reserve.

ii). Subsequent to the artificial activities (otherwise termed treatment) on the experimental field, the response are keenly observed while the plants are allowed to remain within their natural environment.

This spatial variability has thus been incorporated into experimental agriculture where experimental activities are also based partly on natural phenomenon. Conceptually, the clear message is that uncertainty in the similarity of spatial points can be hinged on the analogy of spatial variability of other aggregate factors that enhances or inhibits the growth of such parameters. In as much as patchiness (the degree to which individuals are aggregated or dispersed) have been found to be crucial to how a species uses resources and to its reproductive biology, this study have also established that the spatial variability of the parameter is also crucial. This would chart the direction of the treatment to be applied on the field and at what coordinate such treatment should be concentrated.

In conclusion, the causes of spatial heterogeneity in any experimental field notwithstanding, spatial randomness and autocorrelation are real and are of valid concern. If it is neglected it can make the results of statistical experimentation and analysis untrustworthy. Based on these therefore, it could be recommended that the effects of plant type/ or species on the spatial variation in experimental plots is also recommended for further studies and method of patchiness delineation and definition needs to be evolved.

\section{REFERENCES}

Benwell GL, McLennan Grasberger T, Fryer J (2002). Spatial data analysis for aboriginal rock extraction sites at Brewarrina, NSW, Australia. Presented at the $14^{\text {th }}$ Annual Colloquium of the Spatial Information Research Centre held at Victoria University of Wellinghton, Wellinghton, New Zealand between December $3^{\text {rd }}-5^{\text {th }}$ 2002, p. 11.

Dauda TO, Ojo LO, Nokoe SK (2003). Height - Diameter Model of Some Tree Species in a Natural Forest. J. Trop. For. Resour. Department of Forestry, University of Ibadan, Ibadan, Nigeria, Vol 19(1): 200-219.

Fagroud M, Meirvenne MV (2002). Accounting for Soil spatial Autocorrelation in the Design of Experimental Trials. Soil Sci. Society Am. J. 66: 1134-1142.

Fike WT (1990). The rise and fall of kenaf as a fibre crop in North Carolina. In Janick J, Simon J (eds). Advances in New crops. Portland, OR; Timber press, pp. 297-299.

Fulton JP, Wells LG, Shearer SA, Barnhisel (1996). Spatial variation of 
soil physical properties; A precursor to precision tillage. ASAE paper No 961002, International Meeting, Phoenix, Arizonia, July $14-18$, 1996 p. 24

Liebhold AM, Gureitch J (2002). Integrating the statistical analysis of spatial data in ecology. ECOGRAPHY, 25: 553-557.

Pfoser D, Jensen C, Theodoridis $Y(2000)$. Novel approaches to the indexing of moving object Tranjenctories. VLDB, pp. 395-406.

Presinger H, Coelho LF, Gasparotto L, Lieberei R (2000). Spatialand temporal changes of spontaneous vegetation in Agricultural field

Richard J, Dean W (1998). Applied Multivariate Statistical Analysis, Prentice Hall, 1998, 2nd edition, p. 607.
Schanbenberger O, Pierce FJ (2002). Contemporary Statistical Models for the Plant and Soil Science. Washington, D.C; CRC Press, p. 738. Song C, Kulldorff K (2008). Stat. Med. Vol. 15. 25(5): 825 -839.

Vieira SR, Gozalez M (2003). Analysis of the spatial variability of crop yield and soil properties in small agricultural plots; Brigantia Capinas, 6(1):127-138. 